\title{
Telemedicine as a part of globalization and tool for innovation from the legal point of view
}

\author{
Martin Orviský1,1, and Jaroslav Klátik ${ }^{1}$ \\ ${ }^{1}$ University of Matej Bel in Banská Bystrica, Faculty of Penal Law, Criminology, Criminalistics and \\ Forensic Sciences, Komenského 20, 97401 Banská Bystrica, Slovakia
}

\begin{abstract}
.
Research background: The use of various information systems is currently beginning to be increasingly promoted also in the area of provision of health care. This is the so-called telemedicine and nowadays can by considared as standard - the prescribing of electronic prescriptions, enrolling in a doctor's waiting room online and so on. One of the last services in telemedicine was the introduction of a video-call with a doctor as a form of teleconsultation. However, the video-call with the doctor is not recognized by the current law and allows it to be performed only as an emergency form of replacement of medical examination during a pandemic-related emergency. The use of telemedicine for that raises a number of serious legal issues that need to be solved.

Purpose of the article: The main purpose of article is deal with the use of information systems in medicine and analyze the possibility and permissibility of using telemedicine from the legal point of view. The authors therefore analyze the possibility of providing certain acts in medicine and acts related to medical examinations online and analyze what conditions of personal data protection must be maintained in this case.

Methods: The authors use the method of analysis, synthesis, systemstructural method and normative-legal method of interpretation of legal norms.

Findings \& Value added: The main benefit of the research is the analysis of the conditions that a doctor must observe when providing telemedicine in order to provide healthcare in accordance with the law and proposals for the regulation of telemedicine de lege ferenda.
\end{abstract}

Keywords: Telemedicine ; Personal data protection ; Provision of health care

JEL Classification: K19; K23; K32

\footnotetext{
${ }^{1}$ Corresponding author: orvisky.martin@gmail.com
} 


\section{Research background}

Electronization is gradually penetrating all areas, including medicine and law. Currently in the Slovak Republic, a visit to the doctor can be arranged online, through telecommunication devices it is possible to check how many patients the doctor has physically in the waiting room, prescriptions are issued electronically by the doctor so that a personal visit to the doctor is not necessary, etc. Abroad for example, in the United Kingdom of Great Britain and Northern Ireland are used electronic records, disease management applications, clinical warnings and reminders, and electronic monotoration systems. At the same time, patient monitoring applications are already being actively used abroad (in some countries), which may include wearable sensors that monitor the patient's vital signs and immediately transmit the acquired data to the physician.[1]

In connection with the development of electronization in medicine, the term (which we also mentioned above) is used more and more often. "Telemedicine". The theory recognizes the terms "telemedicine" and "telehealt", but the World Health Organization often identifies these terms in its publications, and therefore we will not distinguish between the terms "telemedicine" and "telehealt" in this paper, but will use the single term "telemedicine".

In the USA, telemedicine is defined as: "use of electronic information and telecommunications technologies to support and promote long-distance clinical health care, patient and professional health-related education, public health and health administration." It is a digital solution in health care that can provide quality care, increase timely access, minimise travel distances and reduce costs.[2] The World Health Organization explains the concept of telemedicine as: "the provision of healthcare where distance is a decisive factor, all healthcare professionals using information and telecommunications technologies to exchange valid information for the diagnosis and prevention of disease and injury, research and evaluation, and other education of healthcare providers, all in order to improve the health of individuals and their communities. In view of definitions above, the World Health Organization further recognizes four characteristics of telemedicine: 1. the purpose of telemedicine is to provide clinical support; 2 . the purpose of telemedicine is to overcome geographical barriers and connect users who are not in the same physical location; 3 . telemedicine involves the use of different types of information and telecommunication technologies; and 4. the aim of telemedicine is to improve health care outcomes. [3] Given the definitions of telemedicine above, it can be said that various forms of telemedicine are currently commonly used in the Slovak Republic. In terms of examples for the current use of telemedicine in the Slovak Republic, it is possible to mention the issuance of electronic prescriptions by doctors online (so-called "e-Recepty", where the patient does not have to physically come to the doctor's office, but the prescription is issued electronically) and the patient will pick up the prescribed medication directly in the pharmacy, health assessment and instructions for the participants in the accident by phone (the doctor on the phone advises the accident participant on how to proceed to save a life until the emergency services arrive), etc. Of course, telemedicine has several benefits, and in terms of contributions from the USA Telemedicine Conference, one of the main benefits of telemedicine is that it balances the differences between urban and rural medical environments, leads to better disease management, improves the potential for evidence-based standards and reduces costs. for the provision of healthcare at several levels (both on the part of doctors and on the part of patients).[4] In addition, recent studies in the USA have found that providing telemedicine healthcare in the United States saves the patient an average of two hours to travel to the physician and, of course, the financial resources he or she would spend on the trip.

In addition, the coronavirus pandemic accelerated the development of the use of information and telecommunication technologies in medicine, and currently, in addition to the above examples of the use of telemedicine, consultations with a doctor via video call have 
begun to be used in the Slovak Republic. The reason why the pandemic has contributed to the development of telemedicine is that telemedicine is the ideal tool for managing communicable diseases. A key factor in slowing down the transmission of the virus is social distance and reduced physical contact between people. For patients infected with COVID-19 or for people who may be infected, telemedicine can help with remote assessment of their health and the provision of healthcare. On the other hand, telemedicine for people who are not infected can provide convenient access to routine care without the risk of being infected in a crowded hospital or waiting room in a doctor's office.[5] In addition, recent studies in the United States have found that providing telemedicine healthcare in the United States saves the patient an average of two hours to travel to the physician and, of course, the financial resources he or she would spend on the trip.[6]

It is essential to emphasize that the use of telemedicine requires a skilled health workforce who is also able to provide the technical side of telemedicine. Telemedicine requires doctors to learn new methods of consultation and thus their willingness to learn to use new means of telecommunication and to use telemedicine in practice. Therefore, it is essential that the various uses of telemedicine become part of teaching in medical schools. However, telemedicine also has its limitations. Some act of health care require physical examinations, which can be difficult to perform remotely and diagnosis, respectively examination that cannot be performed remotely at all. Therefore, as the Australian study points out, it is essential that the training of doctors to practice telemedicine also emphasizes the limitations of telemedicine and inform doctors about alternative methods of gathering information that cannot be used in this situation.[5] At the same time, it is necessary to think about the financial side of telemedicine (a doctor may have significant initial expenses with the introduction of telemedicine) and motivate doctors to use it financially. Despite this statement, it must be emphasized (as stated in several publications, in particular a paper from a conference in the USA presenting a healthcare facility that introduced the full use of telemedicine in healthcare), that telemedicine should be provided for the benefit of the patient, not for profit ( however, in our opinion this idea can be applied to medicine in general). Telemedicine is therefore about expanding services that improve the profile of the healthcare provider.[4]

In view of the above, the studies dealing with the use of telemedicine in the fight against the COVID-19 pandemic recommend, as an appropriate measure, the temporary financing of certain telemedicine services.[5] In some states as the USA, the use of telemedicine became recommended as a standard of care in some situations, for example for infantile spasms.[7] The development of telemedicine has taken place in several countries around the worldand states began to introduce various forms of telemedicine. Several studies also point out that the use of telemedicine is beneficial both during and outside the pandemic.[8] In the USA was established a COVID 19 virtual clinic.[9] In Italy was (during the second wave of pandemic) developed new models for pulmonary rehabilitation using telemedicine.[10] In Brazil, telemedicine is not legally enshrined (similarly as in the Slovak Republic), but in response to the growing impact of the pandemic the Brasil gouverment expanded the use of technology to other areas in medicine, such as teleconsultations and remote case monitoring.[11] And in Spain was developed a household follow-up proposal for COVID-19 patients by adapting TELEA system - a web-based electronic tool, originally designed as a home monitoring system for chronic patients. TELEA is a digital platform that allows any patient at home (with a tablet, a personal computer, or a smart phone) to record the clinical variables defined by their physicians. The patient can fill in questionnaires on the platform (symptoms, life quality, etc.) and register different clinical variables (temperature, heart rate, etc.). These data are directly uploaded to the patient's electronic medical record, so the health care team can track the patient in real time. The platform generates various alarms according to the collected parameters, which are used as a guide for monitoring and clinical decision 
making. It also allows to call the patient by phone, make a videoconference, or send an email.[12]

It was this aspect that was also reflected by health insurance companies in the Slovak Republic. During the pandemic of COVID-19, all health insurance companies included in the reimbursed acts of health care some acts of the so-called telemedicine. With this step, health insurance companies tried to contribute to the use of telemedicine and began to reimburse separately pre-defined telemedicine activities. The doctor thus obtained extra funds from the insurance company for performing telemedicine services, which may contribute to the right to use telemedicine. Health insurance companies in the Slovak Republic have specifically introduced reimbursement of the following items and telemedicine services: 1. consultation by e-mail or telephone (this is an act designated as performance $1 b)$; 2 . crisis psychotherapeutic intervention through electronic communication (this is an action referred to as performance 1c); 3. consultation through enhanced electronic communication in an online environment (web application, video call (this is an act 11a), and 4. re-issuing medical prescriptions and / or at the patient's request by e-mail, SMS or telephone.[13] In order to grant payment for the above services, the doctor must properly report these services in the patient's medical records, which is associated with a considerable administrative burden.

Despite the undeniable advantages of telemedicine, whether in the provision of healthcare or in the fight against communicable diseases, in practice there are several fundamental problems associated with the use of telemedicine that need to be addressed in the use of telemedicine. There are also problems with the introduction of telemedicine in high-income countries such as the United Arab Emirates. [14] Within the research of telemedicine in the world, several studies have been prepared, which focused precisely on the identification of these problem areas. In the light of these studies, it can be concluded that the problems related to the introduction of telemedicine can be divided into six basic areas, namely 1 . user-related challenges (this challenge includes different levels of digital user literacy, lack of technological acceptance between doctors and patients); 2. infrastructure challenges (this challenge includes in particular communication technologies such as Bluetooth, Wifi, mobile data and their technical characteristics); 3. process challenges (this challenge several issues, including security such as authentication and authorization, confidentiality, ethical issues, etc.); 4. management challenges (this call includes, in particular, quality control of telemedicine use and legislation); 5. resource challenges (this challenge includes in particular hardware, software issues, lack of specialized developers and telemedicine costs); 6. trainingrelated challenges (this challenge includes problems caused by a lack of training and user instruction).[1]

As follows from the presentation of the issue of telemedicine, telemedicine has several uses and its certain forms work stably in the Slovak Republic. In this paper, however, we will further focus mainly on consulting the doctor and patient through a video call in the conditions of the Slovak Republic as the performance of telemedicine from a legal point of view (legal aspect in this case includes process challenges and telemedicine management challenges).

\section{Research methods}

In terms of research methods, we used the method of analysis, structural analysis, synthesis of knowledge, cognitive explication and normative-legal methods of interpretation of legal norms. We also interviewed a video-consulting doctor and analyzed his comments on the provision of telemedicine healthcare from a legal perspective. The basic method that we used in the study of telemedicine in the conditions of the Slovak Republic is the method of analysis and normative-legal methods of interpretation of currently valid legal norms in the Slovak 
Republic concerning telemedicine and regulations that affect this issue. As part of the analysis, we then drew general conclusions based on the knowledge gained from individual and specific problems.

\section{Results}

It is necessary to emphasize that it is not possible to provide health care in the Slovak Republic through a video call. The Health Care Act recognizes exclusively outpatient, institutional, pharmaceutical and nursing forms of health care provision.[15] This is also confirmed by the performance of 11a reimbursed by health insurance companies, which reimburse doctors exclusively for consultation with patients via video call, as well as the explanatory memorandum to the Health Care Act, which states in Article II point 6 that the introduction of video consultation ) is only a supplement to outpatient healthcare.[16] In summary, it is only possible to provide a consultation via a video call, but it is not possible to replace the medical examination itself with a video consultation.

It is also necessary to emphasize that the law provides for video consultation only during the crisis as a supplement, not a substitute for outpatient care. Therefore, without legislative intervention, it is in principle not possible to use video call consultation as act of health care outside of a crisis situation. The crisis situation is defined in Constitutional Act no. 227/2002 Coll. on the security of the state in time of war, state of war, state of emergency and state of emergency. According to this definition, "A crisis situation is a period during which the security of the state is immediately endangered or disturbed and the constitutional authorities may, after fulfilling the conditions laid down in this constitutional law to resolve it, declare war, declare a state of war or state of emergency or state of emergency." this legislative entrenchment means that the performance of telemedicine through a video call is possible only during a threat to the security of the state, such as current coronavirus pandemic. However, without a crisis situation (eg after a pandemic), the use of some telemedicine services that are linked to a crisis situation (such as a video call consultation) is not possible.

Therefore, if telemedicine should be used in the future in the provision of health care, such as. constant monitoring of the patient's health by means of telecommunication technology, resp. determination of the diagnosis exclusively on the basis of measurements performed by devices recommended by a doctor at a distance, etc. major legislative intervention is needed. In this context, it can be noted that the authors of foreign studies, in terms of the challenge of management, clearly recommend the adoption of the necessary legislation for the effective use and management of telemedicine. [1]

At the same time, the doctor often does not have the necessary hardware and software to be able to provide a secure video call (from a data security point of view) and therefore (if he wants to provide these services for his patients) usually has to turn to third party services. These are mainly companies that will provide these patient consultations via video call (with the required level of data security). As part of the research and preparation of this article, we conducted a market research in connection with the provision of video calls for physicians by third parties. This survey shows that currently this service for doctors in the Slovak Republic is provided mainly by two trading companies, namely the company eČasenka, s.r.o. and CompuGroup Medical, s.r.o. (This survey did not take into account the situation where the doctor or hospital arranged a video consultation with the doctor himself through his own resources). The doctor's consultation with the patient via video call (based on a description from the official website of both companies) in this case takes place in such a way that the patient must first register with the service provider. The service provider then assigns the patient a special code with an Internet link (which is delivered to the patient by e-mail), through which the patient gets to the doctor's virtual waiting room. After receiving the code, the patient logs into the virtual waiting room at the time when the doctor provides a 
consultation service via a video call and the doctor then has the opportunity to start a video call with the patient.

However, the described procedure raises several legal issues (which fall under the process challenge and the management challenge), which he pointed out from practice and which we consulted with the outpatient doctor providing video call consultation and which can be divided into three basic categories: 1 . personal data protection; 2 . data security and the related verification of the patient's identity (in order not to provide pacient sensitive personal data related to the health to third party) as well as the consequences of breaching the security of patient data (in terms of physician responsibility); 3. the issue of fulfilling the obligations of a doctor imposed on him by law. Next, from a legal point of view, we will approach the above-mentioned problems, analyze them and at the same time propose a recommendation for a doctor who applies video-video consultation in practice.

\subsection{Personal data protection}

Regulation (EU) 2016/679 of the European Parliament and of the Council of 27 April 2016 concerning the protection of individuals with regard to the processing of personal data and on the free movement of such data and repealing Directive 95/46 / EC (hereinafter "GDPR") considers personal data relating to a natural or mental health of a natural person, including data on the provision of healthcare services, which reveals information about his or her state of health, to be data relating to health. The GDPR generally prohibits the collection and processing of health data. The doctor has an exception in this respect under Article 9 where the processing of health data is necessary for the provision of healthcare. However, this exception does not apply to a third party who provides a video call to your doctor. Therefore, e.g. According to our request, the health insurance companies also stated that the performance of 11a consultation between the doctor and the patient via video call only reimburses if the video call is secured and no third party has a recording of the video call. If a video call recording were to be stored with a person other than a doctor and not a doctor's intermediary in the processing of personal data, such a person would need the explicit consent of the patient to process the health data before processing the data.

Although the physician has a legal basis for the processing of health data as a specific category of personal data, he remains obliged to provide the patient with the following information when obtaining personal data: (a) the identity and contact details of the physician as controller; (b) contact details of the responsible person; (c) the purposes of the processing for which the personal data are intended as well as the legal basis of the processing; (d) the recipients or categories of recipients of the personal data, if any. However, in addition to the above information, the doctor is obliged to provide the patient with information on (a) the retention period of personal data or, if this is not possible, the criteria for determining it; (b) the existence of the right to request from the doctor (or controller) access to personal data concerning the patient and the right to rectify or erase them or to limit the processing, or the right to object to the processing, as well as the right to data portability; (c) information on the right to complain to the supervisory authority; (d) information on whether the provision of personal data is a legal or contractual requirement, or a requirement necessary for the conclusion of the contract, whether the data subject is obliged to provide personal data, and the possible consequences of not providing them; (e) the existence of automated decisionmaking in the processing of personal data. In practice, however, there is a problem in that the doctor does not fulfill this obligation to the patient, respectively. cannot prove its fulfillment. The doctor is not obliged to prove the fulfillment of the obligation to inform the patient in written, but the fulfillment of this obligation can also be proved in another way. In the case of the above information, it is an opportunity for the patient to become acquainted with it, thus fulfilling the principle of transparency of the processing of personal data. 
Information relating to the processing of personal data concerning the data subject should be provided to the data subject at the time the personal data are obtained from the data subject or, if the personal data have been obtained from another source, within a reasonable period of time depending on the case. It is necessary to emphasize that the obligation to provide information to the data subject does not arise only at the request of the patient, but the doctor (as operator) is obliged to provide this information to the patient at the latest when obtaining personal data. The doctor must actively seek to fulfill this obligation, regardless of whether the patient (as the person concerned) is interested in this information or not. The doctor is obliged to perform activities consisting in providing the said information to patients (as affected persons) or in actively directing the attention of patients to the place where information on the processing of personal data is made available (eg by direct redirection link). In terms of the time when the doctor is obliged to provide the patient with information on the processing of personal data, the doctor is obliged to provide the patient with information before obtaining personal data. In other words, the provision of information cannot take place after personal data has been obtained. If the information were provided only after the personal data had been obtained, there would be a violation of Article 13 para. 1 GDPR. [17] The GDPR does not prescribe to the doctor, as the operator, the format or method of fulfilling the information obligation. Article 12 of the GDPR stipulates that information shall be provided in writing or by other means, including, where appropriate, by electronic means. If the patient so requests, the information may also be provided orally, provided that the identity of the person concerned is otherwise established.

Therefore, from the point of view of a practical solution (and at the same time saving time, as the doctor does not have time in his work exclusively to read all the rights of the data subject), it seems appropriate to have a reference to this information for the data subject in the doctor's virtual waiting room. The information is displayed to the patient automatically when entering the virtual waiting room or that this data is displayed to the patient immediately after the start of the video call, e.g. by sharing a document containing this information. However, these solutions can often only be provided with a person who provides the doctor with video call. At the same time, if the doctor has his own website, it is appropriate to place this information in terms of transparency on this website. This should ensure that the patient is informed and that the doctor's obligation to inform the patient as the data subject of his or her rights in relation to the processing of personal data is fulfilled.

\subsection{Authentication and data security}

In the case of data security issues, the doctor is obliged by law to verify the patient's identity when providing a video call consultation. It is a logical requirement that a doctor does not mistake sensitive patient health data to a third party. The explanatory memorandum to the Health Care Act explicitly states that the condition for providing health care by consultation by video call (as a supplement to outpatient health care) is verification of the patient's identity and insurance relationship with his / her respective health insurance company. [16] However, the law does not give doctors any instructions on how to verify a patient's identity remotely. In addition, the regulation of identity verification in connection with the use of telemedicine is not included in any by-law. The explicit legal regulation of remote identity verification in the legal order of the Slovak Republic is contained only in the regulations in the area of concluding distance contracts in banking, which, however, are not applicable in the case of telemedicine.

The doctor should first determine if the video call is in real time, i. that it is not just a recording of a person (patient), thus excluding the possibility of providing sensitive personal data to a third party. Subsequently, in terms of identity verification, it will be necessary, in our opinion, to distinguish the case: 
- when it comes to a patient who is already a doctor-patient at the time of the videoconsultation, was in person with the doctor, the doctor knows him and verified his identity through physical contact in the past;

- when the doctor has never examined the patient in the past and the patient has not been examined by a doctor before (the doctor's first action would be a video call consultation).

In the case of a long-term patient, the doctor has previously physically verified the patient's identity and in principle it is sufficient for the doctor to re-verify the patient's identity through his face (displayed via video call) and pacient personal data (such as first name, last name, and birth number) or by sending a verification text message to the patient's phone number. If the patient's first contact with the doctor is provided via a video call, this is a more complex situation that would require explicit legislation (which is currently absent in the Slovak Republic), as the doctor has never physically seen the patient before and has never verified his identity, for example, it does not have the patient's telephone number or other information that could help him verify the patient's identity). In such a case, it seems to us to be the most reliable in terms of verifying the patient's identity by displaying the policyholder's card, ID card or other identification document on camera. It is necessary to emphasize that without explicit legislative intervention in this area, it is not possible to guarantee that our proposed solution will be in accordance with the requirement to verify the identity of the patient whose first contact with the doctor is through a video call.

In view of the above conclusion, we also analyzed the possibility of a threat of sanctions for the doctor in case of non-compliance with the imposed obligations to verify the patient's identity and the related possibility of entrusting sensitive personal data of the patient to an unauthorized person. In terms of possible sanctions, it is possible to clearly exclude a criminal sanction if the doctor entrusts personal data to a stranger out of negligence (this of course does not exclude the criminal liability of a doctor if he does so intentionally). In this connection, the Slovak Criminal Code recognizes the criminal offense of Unauthorized Use of Personal Data pursuant to Section 374 of the Criminal Code (Who illegally provides, makes available or discloses a) personal data about another collected in connection with the exercise of public power or exercise of constitutional rights on another acquired in connection with the performance of his profession, employment or function and thereby violates a generally binding legal regulation), which is an intentional criminal offense. Although in the given case from the point of view of the objective aspect of the crime of Unauthorized Use of Personal Data - in the case of personal data processing by a doctor, the presumption would be fulfilled that the doctor obtains personal data in connection with the exercise of his profession, or entrust personal data to a third party, the subjective aspect of the crime of Unauthorized Handling of Personal Data is not fulfilled and therefore the negligent conduct of a doctor in this case cannot be punished as a criminal offense. This, of course, does not affect sanctions against a doctor for breach of personal data protection and the patient's right to compensation in the event of its occurrence.

\subsection{The doctor's obligation to inform the patient about the course of treatment}

At the same time, in terms of his duties, the doctor must not neglect the patient's medical documentation and the performance of telemedicine - record the consultation via video call in the patient's medical documentation. In addition, in the term of $\S 6$ of the Health Care Act doctor is generally obliged to inform pacient about the purpose, nature, consequences and risks of providing health care, about the possibilities of choosing the proposed procedures and risks of refusing to provide health care, while the patient subsequently gives the doctor informed consent, which may not always be in writing. Therefore, in cases where the law does not explicitly require the written informed consent of the patient, it will be sufficient to 
prove the provision of information to the patient about the treatment and his consent to this treatment, e.g. through a video recording. The problem occurs if the doctor wants to e.g. change the treatment procedure after video-consultation with the patient (or another act for which the law explicitly requires the written form of the patient's informed consent), because if there is a change in the treatment procedure that was not part of the prior informed consent, the law requires the patient to inform consent was given in writing. However, again in the case of a video-call consultation, the law does not respond to this fact and does not allow the doctor to obtain informed consent, e.g. by electronic means (of course, consent would be given in writing even if the patient signed an electronic document containing informed consent with his guaranteed electronic signature, but this requires some technical literacy on the part of the patient and several technical conditions for his consent) which cannot be achieved in the current situation in all patients. Nevertheless, in view of the crisis situation, we believe that in this case, the doctor should inform the patient at least through a video call and prove the patient's consent, at least through a recording. Although this procedure will not explicitly comply with the provisions of the Health Care Act, the doctor will be able to prove the fulfillment of his duties and the granting of consent, which may be necessary in the event of control by the health care supervisory authority.

\section{Summary and discussion}

In conclusion and for a possible discussion, it is possible to summarize that certain telemedicine activities are used in practice in the Slovak Republic. It is necessary to emphasize that new telemedicine services (such as video call consultation as an adjunct to outpatient care) have been allowed in the coronavirus pandemic, but are exclusively linked to the duration of the crisis. Studies from abroad have shown that telemedicine can improve healthcare delivery. However, it is essential that telemedicine is properly enshrined in legislation (which is also required by the management challenges of introducing telemedicine) and any legislative entrenchment or by-laws must define clear boundaries and procedures for physicians in performing telemedicine (e.g. in terms of verification identity of the patient, the protection of personal data and the provision of informed consent of the patient, as the current legislation does not provide clear procedures for doctors). We believe that enshrining telemedicine in legislation will be beneficial and the potential for its use is beyond crisis. However, the question for discussion remains how to legislatively set the conditions for patient identification, consent and data security and what procedures to recommend to physicians in the practice of telemedicine in terms of the issues discussed.

\section{References}

1. Baniasadi, T., Kalhori, S.R.N., Ayyoubzadeh, S.M., Zakerabasali, S., Pourmohamadkhan, M. (2018). Study of challenges to utilise mobile-based health care monitoring systems: A descriptive literature review. Journal of Telemedicine and Telecare, 24(10), 661-668

2. Gali, K., Joshi, S., Hueneke, S., Katyenbach, A., Radecki, L., Calabrese, T., Fletcher, L., Trandafir, C., Wilson, C., Gozal, M., Wusthoff, C.J., Le Pichon, J.B., Corvalan, R., Golson, A., Jessica, H., Smith, M., Cook, E. Bonkowskz, J.L. (2020, November 12.). Access and management of pediatric epilepsy with telehealth. https://journals.sagepub.com/doi/full/10.1177/1357633X20969531

3. WHO Library Cataloguing-in-Publication Data Telemedicine (2020, September 3). Opportunities and developments in Member States: report on the second global survey on eHealth 2009. WHO. 
https://www.who.int/goe/publications/goe_telemedicine_2010.pdf

4. Alverson, D., Krupinski, E., Erps, K., Rowe, N., Weinstein, R. (2019). Case Report The Third National Telemedicine \& Telehealth Service Provider Showcase Conference: Advancing Telehealth Partnerships. TELEMEDICINE and e-HEALTH, 25(4), 332 340.

5. Smith, A., Thomas, E., Snoswell, C., Haydon, H., Mehrothra, A., Clemensen, J., Caffery, L. (2020). Telehealth for global emergencies: Implications for coronavirus disease 2019 (COVID-19). Journal of Telemedicine and Telecare, 26(5), 309-313.

6. Kruse, C.S., Karem, P., Shifflett, K., Vegi, L., Ravi, K., Brooks, M. (2018). Evaluating barriers to adopting telemedicine worldwide: A systematic review. Journal of Telemedicine and Telecare, 24(1), 4-12.

7. Zachary, M., Grinspan, M.D., Mztinger, J.R., Baumer, F.M., Ciliberto, M.A., Cohen, B.H., Dlugos, D.J., Harini, Ch., Hussain, S.A., Joshi, S.M., Keator, C.G., Knupp, K.G., McGoldrick, P.E., Nickejls, K.C., Park, J.T., Pasupuleti, A., Patel, A.D., Pomeroz, S.L., Shahid, A.M., Shellhaas, R.A., Shrez, D.W., Singh, R.K., Wolf, S.M., Zoyawity, E.G., Yuskaitis, Ch.J., Waugh, J.L., Pearl, P.L., The Child Neurologz Societz et al. (2020). Crisis standard of care: management of infantile spasms during COVID-19. Annals of Neurology, 82(2), 215-217.

8. Fomin, V., Moiseev, S., Yavorovsky, A., Umbetova, K., Brovko, M., Avdeev, S. (2020). Letter to the Editor: Virtual Care for Criticaly Patients with COVID-19. TELEMEDICINE and e-HEALTH, 26(11), 1326-1327.

9. Jethwa, T., Ton, A., Paredes Molina, C.S., Speicher, L., Walsch, K., Knight, D., Davlantes, T., Francis, D. (2020). Establishing Mayo Clinic's Coronavirus Disease 2019 Virtual Clinic: A Preliminary Communication. TELEMEDICINE and e-HEALTH, 26(11), 1419-1423.

10. Giasanti, D. (2020). The Italian Fight Against the COVID-19 Pandemic in the Second Phase: The Renewed Opportunity of Telemedicine. TELEMEDICINE and e-HEALTH, 26(11), 1328-1331.

11. Nascimento, B.R., Brant, L.C.C.T., Castro, A.C., Froes, L.E.V., Ribeiro, A.L.P., Cruy, L.V., Araujo, C.B., Souya, Ch.F., Froes, E.T., Souya, S.D. (2020, October 26.). Impact of a large-scale telemedicine network on emergency visits and hospital admissions during the coronavirus disease 2019 pandemic in Brazil: Data from the UNIMED-BH system. Journal of Telemedicine and Telecare, 0(0), 1-8. https://journals.sagepub.com/doi/full/10.1177/1357633X20969529

12. Rabunal, R., Suarez-Gil, R., Golpe, R., Martiney-Garcia, M., Gomey-Mendey, R., Romaz-Lema, E., Perey-Lopey, A., Rodrigues-Alvarey, A., Bal-Alvaredo, M. (2020). Usefulness of a Telemedicine Tool TELEA in the Management of the COVID-19 Pandemic. TELEMEDICINE and e-HEALTH, 26 (11)1 1332-1335.

13. DOVERA Zdravotná poist'ovňa, a.s. (2020, September 3). https://www.dovera.sk/lekar/aktuality/4021-stanovisko-dovery-k-aktualnejepidemiologickej-situacii

14. Nair, S.C., Satish, K.P., Sreedharan, J., Muttappallymyalil, J., Ibrahim, H. (2020). Improving Health Literacy Critical to Optimize Global Telemedicine During COVID19. TELEMEDICINE and e-HEALTH, 26(11), 1325.

15. National Council of the Slovak republic (2004). Act no. 576/2004 Coll. Health Care act as amendent.

16. Explanatory memorandum to the law no. 125/2020 Coll. (2020. September, 3). https://www.najpravo.sk/dovodove-spravy/rok-2020/125-2020-z-z.html 
17. Hudecová, I., Cyprichová, A., Makatura, I. a kol. (2018). Nariadenie o ochrane fyzických osôbpri spracúvani osobných údajov. Vel'ký komentár. Bratislava : Eurokodex. 